\title{
Inhibition of Recombinant D-Amino Acid Oxidase from Trigonopsis variabilis by Salts
}

\author{
Jessica Kopf, ${ }^{1}$ Daniel Hormigo, ${ }^{1}$ José Luis García, ${ }^{2}$ Carmen Acebal, ${ }^{1}$ \\ Isabel de la Mata, ${ }^{1}$ and Miguel Arroyo ${ }^{1}$ \\ ${ }^{1}$ Departamento de Bioquímica y Biología Molecular I, Facultad de Ciencias Biológicas, Universidad Complutense de Madrid, \\ José Antonio Novais 2, 28040 Madrid, Spain \\ ${ }^{2}$ Departamento de Biología Medioambiental, Centro de Investigaciones Biológicas (CSIC), Ramiro de Maeztu 9, 28040 Madrid, Spain
}

Correspondence should be addressed to Miguel Arroyo, arroyo@bbm1.ucm.es

Received 13 May 2010; Accepted 1 January 2011

Academic Editor: David Ballou

Copyright () 2011 Jessica Kopf et al. This is an open access article distributed under the Creative Commons Attribution License, which permits unrestricted use, distribution, and reproduction in any medium, provided the original work is properly cited.

Inhibition of recombinant D-amino acid oxidase from Trigonopsis variabilis (TvDAAO) activity in the presence of different sodium salts and potassium chloride is reported. A competitive inhibition pattern by sodium chloride was observed, and an inhibition constant value of $K_{i}=85 \mathrm{mM}$ was calculated. Direct connection of $\mathrm{NaCl}$ inhibition with FAD cofactor dissociation was confirmed by measuring the fluorescence of tryptophanyl residues of the holoenzyme.

\section{Introduction}

D-amino acid oxidase (EC 1.4.3.3, DAAO) is a flavoprotein that catalyzes the enantioselective oxidative deamination of D-amino acids to yield the corresponding $\alpha$-imino acids, which are spontaneously hydrolyzed to $\alpha$-oxoacids and ammonia. Reoxidation of the reduced FAD by molecular oxygen is accompanied by the release of hydrogen peroxide $[1,2]$. DAAO is almost ubiquitous in eukaryotic organisms and fulfills different physiological functions: from a catabolic role in yeasts, which allows the use of D-amino acids as carbon and energy sources, to a regulatory role in the human brain, where it controls the levels of the neuromodulator Dserine $[3,4]$.

In recent years, a major biotechnological application of DAAOs has emerged for the industrial production of 7aminocephalosporanic acid (7-ACA), a key starting material for the preparation of semisynthetic cephalosporin antibiotics [5]. D-amino acid oxidases can catalyze the conversion of cephalosporin C to glutaryl-7-aminocephalosporanic acid (glutaryl-7-ACA), the first intermediate in the two step route that leads to 7-ACA. In the second step of the process, glutaryl-7-ACA is hydrolyzed to 7-ACA by a glutaryl-7-ACA acylase, an enzyme from the group of penicillin amidohydrolases (EC 3.5.1.14) [6]. DAAOs from several microbial sources have been demonstrated to work efficiently in the oxidative deamination of cephalosporin C [7-10] whereas DAAO from pig kidney ( $p k \mathrm{DAAO})$ has been considered a poor catalyst in the same reaction [10]. In fact, immobilized Trigonopsis variabilis cells with D-amino acid oxidase activity are actually the most employed biocatalyst for 7ACA production in industry [11]. Cloning of the DAAO gene of T. variabilis in different hosts, such as Escherichia coli [12-16], Saccharomyces cerevisiae, Kluyveromyces lactis [17], Schizosaccharomyces pombe [18], and Pichia pastoris $[19,20]$, has allowed obtaining the recombinant enzyme for biotechnological applications. In many cases, overproduction of hexahistidine-tagged TvDAAO has been successfully achieved in order to obtain an engineered form of the protein that could facilitate its downstream processing in E. coli [12-16] and P. pastoris [20]. As reported previously, a chimeric TvDAAO containing a hexahistidine tag at the $\mathrm{N}$-terminal end was largely expressed as apoenzyme by a recombinant E. coli strain [12], and the pure apoprotein could be purified in a single step by using metal-chelate affinity chromatography. The holoenzyme could be reconstituted from the recombinant apoenzyme by addition of exogenous FAD to yield a fully active enzyme. The dissociation constant $\left(K_{d}\right)$ for FAD of this TvDAAO, which was quite similar of that reported for $p k \mathrm{DAAO}$, is 10 -fold larger than that for 
Rhodotorula gracilis DAAO [21]. Thus, the weak noncovalent binding of FAD to the recombinant enzyme might explain the observation that the flavin cofactor is lost upon dilution or prolonged dialysis [22]. In the present paper, we report experiments demonstrating that recombinant TvDAAO activity was inhibited by different salts and that the direct inhibition by $\mathrm{NaCl}$ is due to $\mathrm{FAD}$ dissociation as confirmed by measuring the fluorescence of tryptophanyl residues of the holoenzyme.

\section{Materials and Methods}

2.1. Chemicals. D-alanine, 2,4-dinitrophenyl-hydrazine (DNPH), EDTA, FAD, imidazolem, and 2-mercaptoethanol were supplied by Sigma. Potassium phosphate, potassium hydroxide, and glycerol were purchased from Scharlab (Barcelona, Spain).

2.2. Enzyme Purification. His-tagged D-amino acid oxidase from Trigonopsis variabilis ( $\mathrm{T} v \mathrm{DAAO}$ ) was produced and purified as previously described in [12]. Recombinant $\mathrm{T} v \mathrm{DAAO}$ was largely expressed as apoenzyme (about 90\%), and further enzyme purification and dyalisis against the appropriate buffer lead to a $100 \%$ pure apoenzyme preparation. This apoenzyme solution was further dialyzed against $20 \mathrm{mM}$ potassium phosphate buffer $\mathrm{pH} 8.0,20 \%$ glycerol, $5 \mathrm{mM}$ EDTA, and $5 \mathrm{mM} \beta$-mercaptoethanol at $4^{\circ} \mathrm{C}$ and, then, centrifuged at $11,600 \times \mathrm{g}$ for 5 minutes. An excess of exogenous cofactor FAD (5-fold enzyme concentration) was added to apoenzyme solution to obtain the holoenzyme solution.

2.3. Protein Determination. Apoenzyme concentration was determined spectrophotometrically using a molar absorption coefficient at $276 \mathrm{~nm}$ of $\varepsilon_{276}=70.5 \mathrm{mM}^{-1} \cdot \mathrm{cm}^{-1}$ [21].

2.4. Enzyme Activity Assay. The standard method measured the release of $\alpha$-ketoacid from $\mathrm{D}$-alanine during the reaction by the formation of the corresponding hydrazone from DNPH, which could be monitored at $450 \mathrm{~nm}$ [23]. The reaction mixture contained $80 \mu \mathrm{l}$ of $100 \mu \mathrm{M}$ FAD dissolved in distilled water and $100 \mu \mathrm{l}$ of $100 \mathrm{mM} \mathrm{D}$-alanine dissolved in $100 \mathrm{mM}$ potassium phosphate buffer $\mathrm{pH}$ 8.0. The mixture was preincubated for 5 minutes at $30^{\circ} \mathrm{C}$, and the reaction was started by adding $20 \mu \mathrm{l}$ of enzyme solution. After 10 minutes, the reaction was stopped with $20 \mu \mathrm{l}$ of a saturated solution (approximately $10 \mathrm{mM}$ ) of DNPH in $1 \mathrm{~N} \mathrm{HCl}$. After 15 minutes of incubation with DNPH, the colour was developed by the addition of $180 \mu \mathrm{l}$ of $2 \mathrm{~N} \mathrm{NaOH}$. Pyruvic acid formation proceeded linearly during the 10-minute reaction period. The activity was calculated by spectrophotometric absorption measurement at $450 \mathrm{~nm}$, using a pyruvic acid calibration curve. All samples were measured three times and the standard error was always below 5\%. One activity unit $(\mathrm{U})$ was defined as the amount of enzyme producing $1 \mu \mathrm{mol}$ of pyruvic acid per minute under the conditions mentioned.

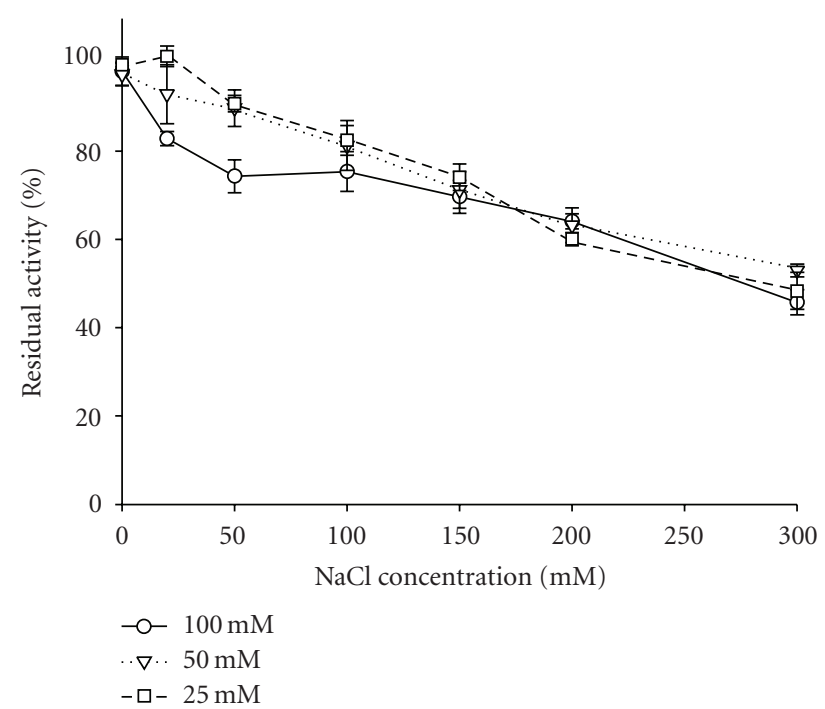

Figure 1: Effect of sodium chloride concentration on recombinant His-tagged TvDAAO activity. Reactions were performed at $25 \mathrm{mM}$ $(\square), 50 \mathrm{mM}(\nabla)$, and $100 \mathrm{mM}(\bigcirc)$ potassium phosphate buffer $\mathrm{pH}$ 8.0 at $30^{\circ} \mathrm{C}$ under the standard assay conditions (see Materials and methods).

2.5. Effect of Inhibitors. Enzyme inhibition by different salts such as $\mathrm{NaCl}$ and $\mathrm{KCl}$ was tested. The activity was assayed at different concentrations of the inhibitor. The activity assay was performed under standard enzyme assay conditions as mentioned above, at a buffer concentration of $50 \mathrm{mM}$.

2.6. Intrinsic Fluorescence Measurements. Intrinsic fluorescence measurements were performed in an SLM Aminco 8000C spectrofluorimeter (Spectronic Instruments, USA) equipped with a thermostated cell holder using a $2 \mathrm{~mL}$ cell at $25^{\circ} \mathrm{C}$. Emission spectra were recorded using an excitation wavelength of $295 \mathrm{~nm}$ (tryptophan emission). Excitation and emission bandwidths were set at $5 \mathrm{~nm}$ and $6 \mathrm{~nm}$, respectively. Scattering was minimized by crossed GlanThompson polarizers.

\section{Results and Discussion}

3.1. Inhibition of Enzyme Activity by Salts. We studied the influence of the presence of different salts on recombinant TvDAAO activity. As shown in Figure 1, we observed a significant decrease of enzyme activity when $\mathrm{NaCl}$ concentration was increased in the reaction medium. At a concentration of $300 \mathrm{mM} \mathrm{NaCl}$, the enzyme only displayed $50 \%$ of the original activity. The influence of buffer concentration on enzyme inhibition was ignored as no differences in activity were observed. The phenomenon of flavoenzyme inhibition by salts has been described in the literature [24-26]. As reported, enzyme inhibition by high salt concentrations often occurs due to the abundance of negatively charged ions, which lead to conformational perturbations preventing holoprotein formation. In fact, flavoproteins that bind their cofactor rather weakly can be deflavinated using bromide 


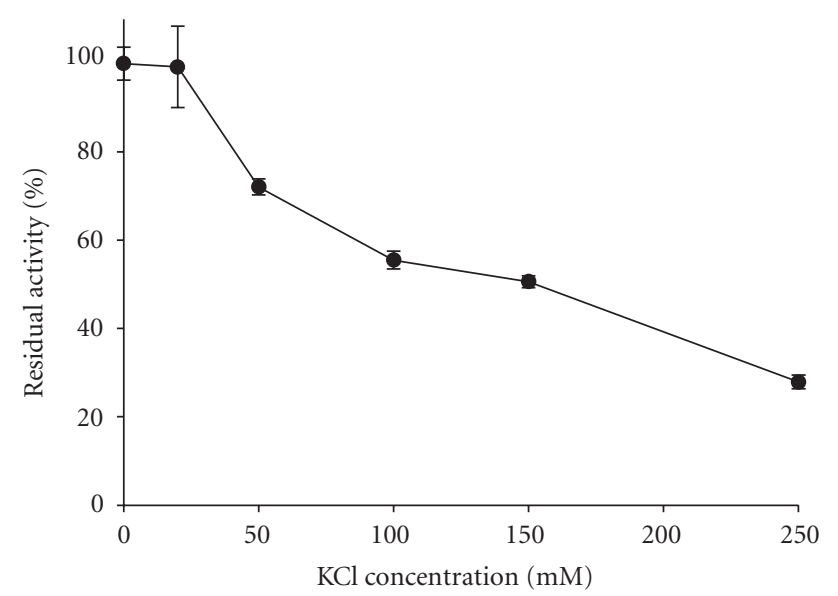

Figure 2: Effect of potassium chloride concentration on recombinant His-tagged TvDAAO activity. Reactions were performed at different salt concentrations in $50 \mathrm{mM}$ potassium phosphate buffer $\mathrm{pH} 8.0$ at $30^{\circ} \mathrm{C}$.

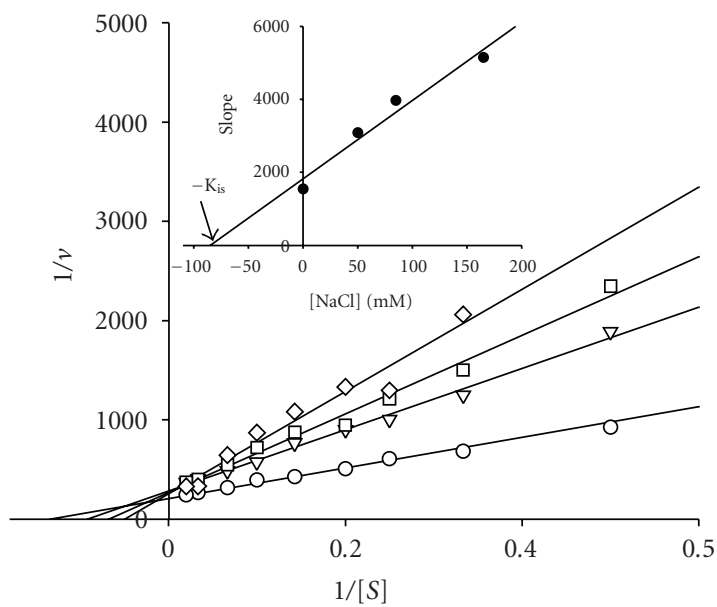

FIgure 3: Competitive inhibition of recombinant His-tagged TvDAAO by sodium chloride. Reactions were performed in $100 \mathrm{mM}$ potassium phosphate buffer $\mathrm{pH} 8.0$ at $30^{\circ} \mathrm{C}$. Sodium chloride concentrations: Nil $(\bigcirc), 50 \mathrm{mM}(\nabla), 85 \mathrm{mM}(\square)$, and $165 \mathrm{mM}(\diamond)$.

ions at high concentration [27-32]. Chloride has been reported to be less chaotropic and therefore less effective in removal of flavin [33]. In our case, reconstituted TvDAAO may be deflavinated in the presence of increasing concentrations of $\mathrm{NaCl}$. As mentioned above, chloride negative charges could interfere with the weak interactions between cofactor and enzyme, favouring FAD dissociation. The same deactivation was observed when $\mathrm{KCl}$ concentration was increased in the reaction medium (Figure 2). Apart from halide ions, also other negative charged groups were described to induce FAD dissociation, such as cyanate or cyanide [24].

3.2. Inhibition by Sodium Chloride. An extensive study of the inhibition effect of recombinant $T v \mathrm{DAAO}$ activity by $\mathrm{NaCl}$

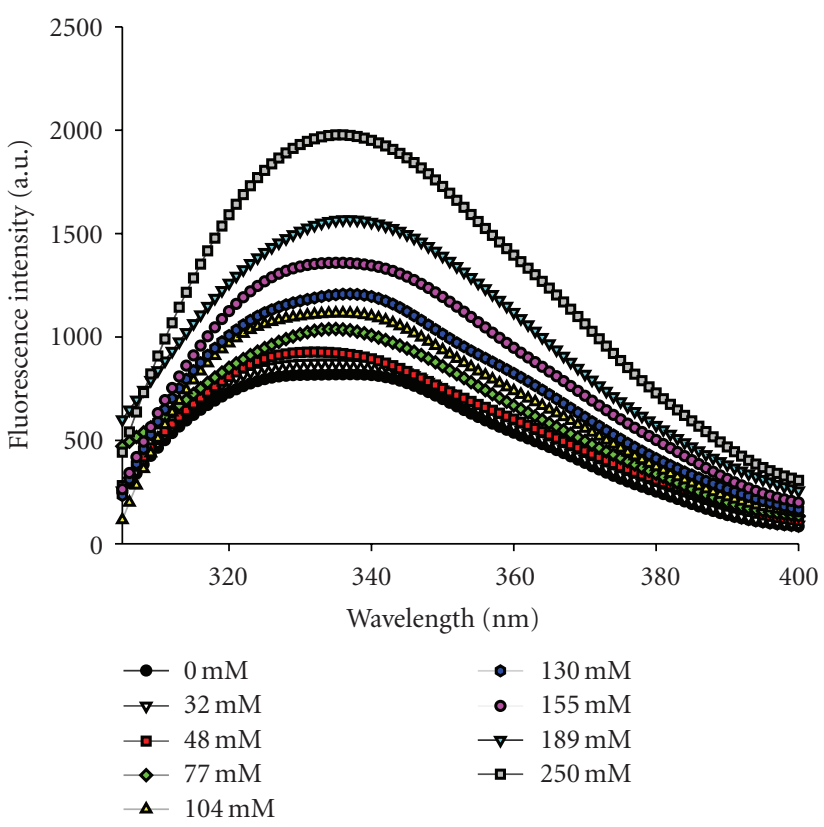

FIGURE 4: Fluorescence emission spectra of recombinant His-tagged $T v \mathrm{DAAO}$ at different sodium chloride concentrations. Intrinsic fluorescence spectra of holoenzyme were recorded at $25^{\circ} \mathrm{C}$ after excitation at $295 \mathrm{~nm}$.

was carried out in order to know the inhibition type and the inhibition constant. The enzyme activity was measured with different concentrations of $\mathrm{D}$-alanine in the absence and presence of several concentrations of sodium chloride under the same standard assay conditions, at $50 \mathrm{mM}$ potassium phosphate buffer $\mathrm{pH}$ 8.0. As shown in Figure 3, the inhibition exerted by $\mathrm{NaCl}$ was competitive, indicating that the chloride anion diminishes the affinity of the enzyme for the substrate, probably due to conformational perturbation of the active site, which could be related to the binding of the negative ion to some residues. Nevertheless, such hypothesis should be checked when the TvDAAO three-dimensional structure will be available. The replot of the slope versus inhibitor concentration fitted to a straight line whose intercept in the $x$-axis indicated an inhibition constant value of $K_{i}=85 \mathrm{mM}$.

3.3. Effect of Chloride Anion on Tryptophanyl Fluorescence of Recombinant TvDAAO. In order to check possible FAD dissociation from the holoenzyme due to $\mathrm{NaCl}$, fluorescence emission spectra of reconstituted TvDAAO in the presence of different $\mathrm{NaCl}$ concentrations were measured with excitation at $295 \mathrm{~nm}$ (Figure 4). Excitation at this wavelength selectively allows measurements of the contribution of tryptophan residues to the emission spectra of the protein. Fluorescence intensity was increased up to threefold when increasing concentrations of $\mathrm{NaCl}$ were added to the enzyme solution. In addition, a small red shift from $338 \mathrm{~nm}$ to $340 \mathrm{~nm}$ was observed, indicating that the tryptophan residues were in a slightly more hydrophilic environment. Such an effect may be related to the loss of cofactor FAD and the corresponding exposure of tryptophan residues, which were quenched by 
the cofactor prior to $\mathrm{NaCl}$ addition. As a matter of fact, TvDAAO apoenzyme, which contains no FAD, shows an emission maximum at $340 \mathrm{~nm}$ with intensity 3-fold higher than that of the holoenzyme, whose maximum is at $338 \mathrm{~nm}$ [21]. The decreased fluorescence intensity of holoenzyme can be explained by a conformational transition upon FAD binding or subunit association that would affect the local environment surrounding the indole ring of tryptophan residues. FAD dissociation from the holoenzyme in the presence of halide anions such as iodide, bromide, or chloride has also been reported for $p k \mathrm{DAAO}$ [28], in which tryptophanyl fluorescence intensity was stronger than that of apoenzyme [27]. In our case, a significant increase of the intrinsic fluorescence intensity can be observed at salt concentrations higher than $77 \mathrm{mM}$. Above this concentration the red shift was also clearly observed. This result is quite similar to the inhibition constant obtained in the kinetic experiments, strongly indicating that competitive inhibition by $\mathrm{NaCl}$ could be related to FAD dissociation. As flavin cofactor binding is essential for catalytic activity, FAD dissociation induced by chloride anions would lead to enzyme inactivation. The same effect has been described for other flavoproteins [24].

\section{Conclusions}

Recombinant TvDAAO activity is inhibited by the presence of high salt concentrations in the reaction media. Sodium chloride behaved as a competitive inhibitor, leading to conformational perturbations in the active site that might induce FAD dissociation.

\section{Acknowledgments}

This work was supported by Universidad Complutense de Madrid and Grupo Santander (Project PR27/05-13880$\mathrm{BSCH})$.

\section{References}

[1] M. S. Pilone, "D-amino acid oxidase: new findings," Cellular and Molecular Life Sciences, vol. 57, no. 12, pp. 1732-1747, 2000.

[2] V. I. Tishkov and S. V. Khoronenkova, "D-amino acid oxidase: structure, catalytic mechanism, and practical application," Biochemistry, vol. 70, no. 1, pp. 40-54, 2005.

[3] L. Pollegioni, L. Piubelli, S. Sacchi, M. S. Pilone, and G. Molla, "Physiological functions of D-amino acid oxidases: from yeast to humans," Cellular and Molecular Life Sciences, vol. 64, no. 11, pp. 1373-1394, 2007.

[4] S. V. Khoronenkova and V. I. Tishkov, "D-amino acid oxidase: physiological role and applications," Biochemistry, vol. 73, no. 13, pp. 1511-1518, 2008.

[5] M. S. Pilone and L. Pollegioni, "D-amino acid oxidase as an industrial biocatalyst," Biocatalysis and Biotransformation, vol. 20, no. 3, pp. 145-159, 2002.

[6] H. D. Conlon, J. Baqai, K. Baker et al., "Two-step immobilized enzyme conversion of cephalosporin $\mathrm{C}$ to 7 aminocephalosporanic acid," Biotechnology and Bioengineering, vol. 46, no. 6, pp. 510-513, 1995.
[7] T. Isogai, H. Ono, Y. Ishitani, H. Kojo, Y. Ueda, and M. Kohsaka, "Structure and expression of cDNA for D-amino acid oxidase active against cephalosporin C from Fusarium solani," Journal of Biochemistry, vol. 108, no. 6, pp. 1063-1069, 1990.

[8] E. Szwajcer-Dey, J. R. Miller, S. Kovacevic, and K. Mosbach, "Characterization of a D-amino acid oxidase with high activity against cephalosporin C from the yeast Trigonopsis variabilis," Biochemistry International, vol. 20, no. 6, pp. 1169-1178, 1990.

[9] M. S. Pilone, S. Buto, and L. Pollegioni, "A process for bioconversion of cephalosporin C by Rhodotorula gracilis Damino acid oxidase," Biotechnology Letters, vol. 17, no. 2, pp. 199-204, 1995.

[10] L. Pollegioni, L. Caldinelli, G. Molla, S. Sacchi, and M. S. Pilone, "Catalytic properties of D-amino acid oxidase in cephalosporin C bioconversion: a comparison between proteins from different sources," Biotechnology Progress, vol. 20, no. 2, pp. 467-473, 2004.

[11] W. Riethorst and A. Reichert, "An industrial view on enzymes for the cleavage of cephalosporin C," Chimia, vol. 53, no. 12, pp. 600-607, 1999.

[12] J. Alonso, J. L. Barredo, P. Armisén et al., "Engineering the D-amino acid oxidase from Trigonopsis variabilis to facilitate its overproduction in Escherichia coli and its downstream processing by tailor-made metal chelate supports," Enzyme and Microbial Technology, vol. 25, no. 1-2, pp. 88-95, 1999.

[13] T. S. Hwang, H. M. Fu, L. L. Lin, and W. H. Hsu, "High-level expression of Trigonopsis variabilis D-amino acid oxidase in Escherichia coli using lactose as inducer," Biotechnology Letters, vol. 22, no. 8, pp. 655-658, 2000.

[14] L. L. Lin, H. R. Chien, W. C. Wang, T. S. Hwang, H. M. Fu, and W. H. Hsu, "Expression of Trigonopsis variabilis D-amino acid oxidase gene in Escherichia coli and characterization of its inactive mutants," Enzyme and Microbial Technology, vol. 27, no. 7, pp. 482-491, 2000.

[15] H. Luo, H. Yu, Q. Li, and Z. Shen, "Cloning and co-expression of D-amino acid oxidase and glutaryl-7aminocephalosporanic acid acylase genes in Escherichia coli," Enzyme and Microbial Technology, vol. 35, no. 6-7, pp. 514$518,2004$.

[16] X. F. Ma, H. M. Yu, C. Wen, H. Luo, Q. Li, and Z. Y. Shen, "Triple fusion of D-amino acid oxidase from Trigonopsis variabilis with polyhistidine and Vitreoscilla hemoglobin," World Journal of Microbiology and Biotechnology, vol. 25, no. 8, pp. 1353-1361, 2009.

[17] F. J. González, J. Montes, F. Martin et al., "Molecular cloning of TvDAO1, a gene encoding a D-amino acid oxidase from Trigonopsis variabilis and its expression in Saccharomyces cerevisiae and Kluyveromyces lactis," Yeast, vol. 13, no. 15, pp. 1399-1408, 1997.

[18] A. Isoai, H. Kimura, A. Reichert et al., "Production of $\mathrm{D}$-amino acid oxidase (DAO) of Trigonopsis variabilis in Schizosaccharomyces pombe and the characterization of biocatalysts prepared with recombinant cells," Biotechnology and Bioengineering, vol. 80, no. 1, pp. 22-32, 2002.

[19] J. Yu, D. Y. Li, Y. J. Zhang, S. Yang, R. B. Li, and Z. Y. Yuan, "High expression of Trigonopsis variabilis D-amino acid oxidase in Pichia pastoris," Journal of Molecular Catalysis B, vol. 18, no. 4-6, pp. 291-297, 2002.

[20] H. Zheng, X. Wang, J. Chen et al., "Expression, purification, and immobilization of His-tagged D-amino acid oxidase of Trigonopsis variabilis in Pichia pastoris," Applied Microbiology and Biotechnology, vol. 70, no. 6, pp. 683-689, 2006. 
[21] M. Arroyo, M. Menéndez, J. L. García et al., "The role of cofactor binding in tryptophan accessibility and conformational stability of His-tagged D-amino acid oxidase from Trigonopsis variabilis," Biochimica et Biophysica Acta, vol. 1774, no. 5, pp. 556-565, 2007.

[22] M. Arroyo, I. de la Mata, M. P. Castillón, C. Acebal, J. L. García, and M. Menéndez, "Inactivation mechanisms of His-tagged D-amino acid oxidase from Trigonopsis variabilis," in Modern Multidisciplinary Applied Microbiology, A. Mendez-Vilas, Ed., pp. 227-231, Wiley-VCH, Weinheim, Germany, 2006.

[23] P. Brodelius, K. Nilsson, and K. Mosbach, "Production of $\alpha$ keto acids Part I. Immobilized cells of Trigonopsis variabilis containing D-amino acid oxidase," Applied Biochemistry and Biotechnology, vol. 6, no. 4, pp. 293-307, 1981.

[24] H. Y. Neujahr, "Effect of anions, chaotropes, and phenol on the attachment of flavin adenine dinucleotide to phenol hydroxylase," Biochemistry, vol. 22, no. 3, pp. 580-584, 1983.

[25] L. Pollegioni, S. Iametti, D. Fessas et al., "Contribution of the dimeric state to the thermal stability of the flavoprotein Damino acid oxidase," Protein Science, vol. 12, no. 5, pp. 10181029, 2003.

[26] M. H. Hefti, J. Vervoort, and W. J. H. van Berkel, "Deflavination and reconstitution of flavoproteins: tackling fold and function," European Journal of Biochemistry, vol. 270, no. 21, pp. 4227-4242, 2003.

[27] V. Massey and B. Curti, "A new method of preparation of Damino acid oxidase apoprotein and a conformational change after its combination with flavin adenine dinucleotide," Journal of Biological Chemistry, vol. 241, no. 14, pp. 3417-3423, 1966.

[28] Y. Nishina, K. Horiike, K. Shiga, Y. Miyake, and T. Yamano, "Effect of halide anions on the binding of FAD to D amino acid oxidase and the tryptophanyl fluorescence of the apoenzyme," Journal of Biochemistry, vol. 81, no. 5, pp. 1455-1463, 1977.

[29] C. C. Ryerson, D. P. Ballou, and C. Walsh, "Mechanistic studies on cyclohexanone oxygenase," Biochemistry, vol. 21, no. 11, pp. 2644-2655, 1982.

[30] P. Casalin, L. Pollegioni, B. Curti, and M. Pilone Simonetta, "A study on apoenzyme from Rhodotorula gracilis D-amino acid oxidase," European Journal of Biochemistry, vol. 197, no. 2, pp. 513-517, 1991.

[31] V. Radjendirane, M. A. Bhat, and C. S. Vaidyanathan, "Affinity purification and characterization of 2,4-dichlorophenol hydroxylase from Pseudomonas cepacia," Archives of Biochemistry and Biophysics, vol. 288, no. 1, pp. 169-176, 1991.

[32] L. Pollegioni and M. S. Pilone, "On the holoenzyme reconstitution process in native and truncated Rhodotorula gracilis Damino acid oxidase," Archives of Biochemistry and Biophysics, vol. 332, no. 1, pp. 58-62, 1996.

[33] S. C. Tu and D. B. McCormick, "Conformation of porcine $\mathrm{D}$-amino acid oxidase as studied by protein fluorescence and optical rotatory dispersion," Biochemistry, vol. 13, no. 5, pp. 893-899, 1974. 

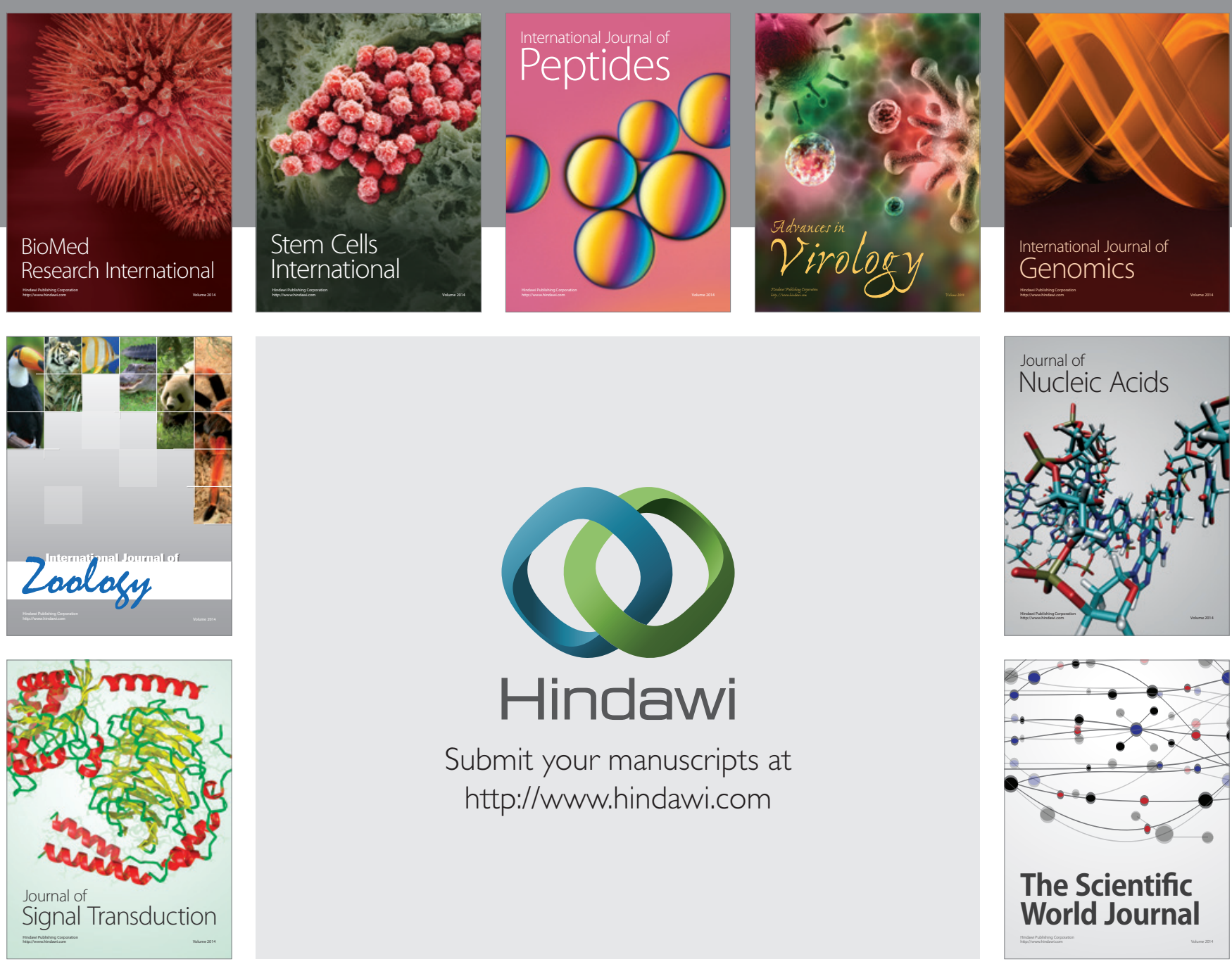

Submit your manuscripts at

http://www.hindawi.com
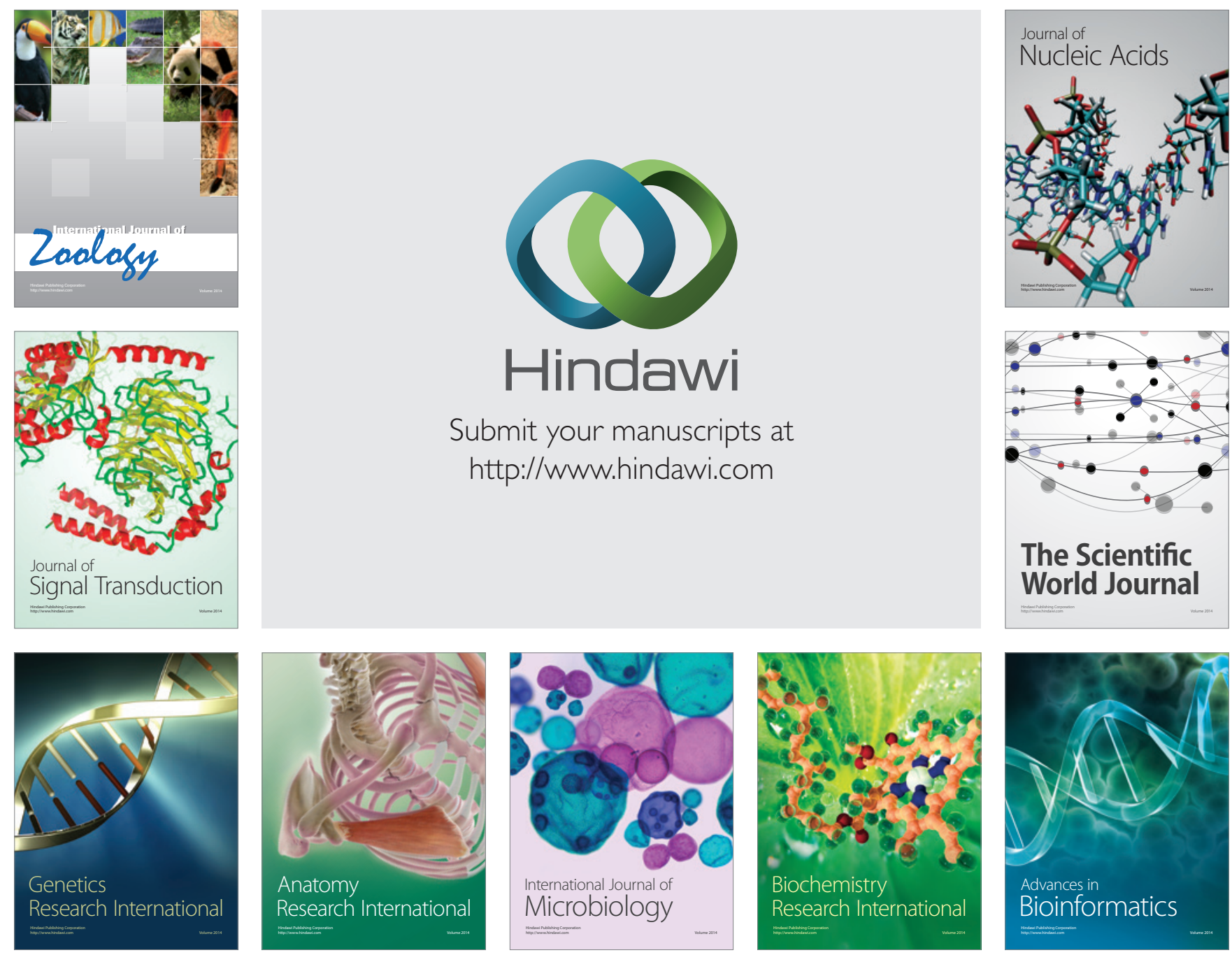

The Scientific World Journal
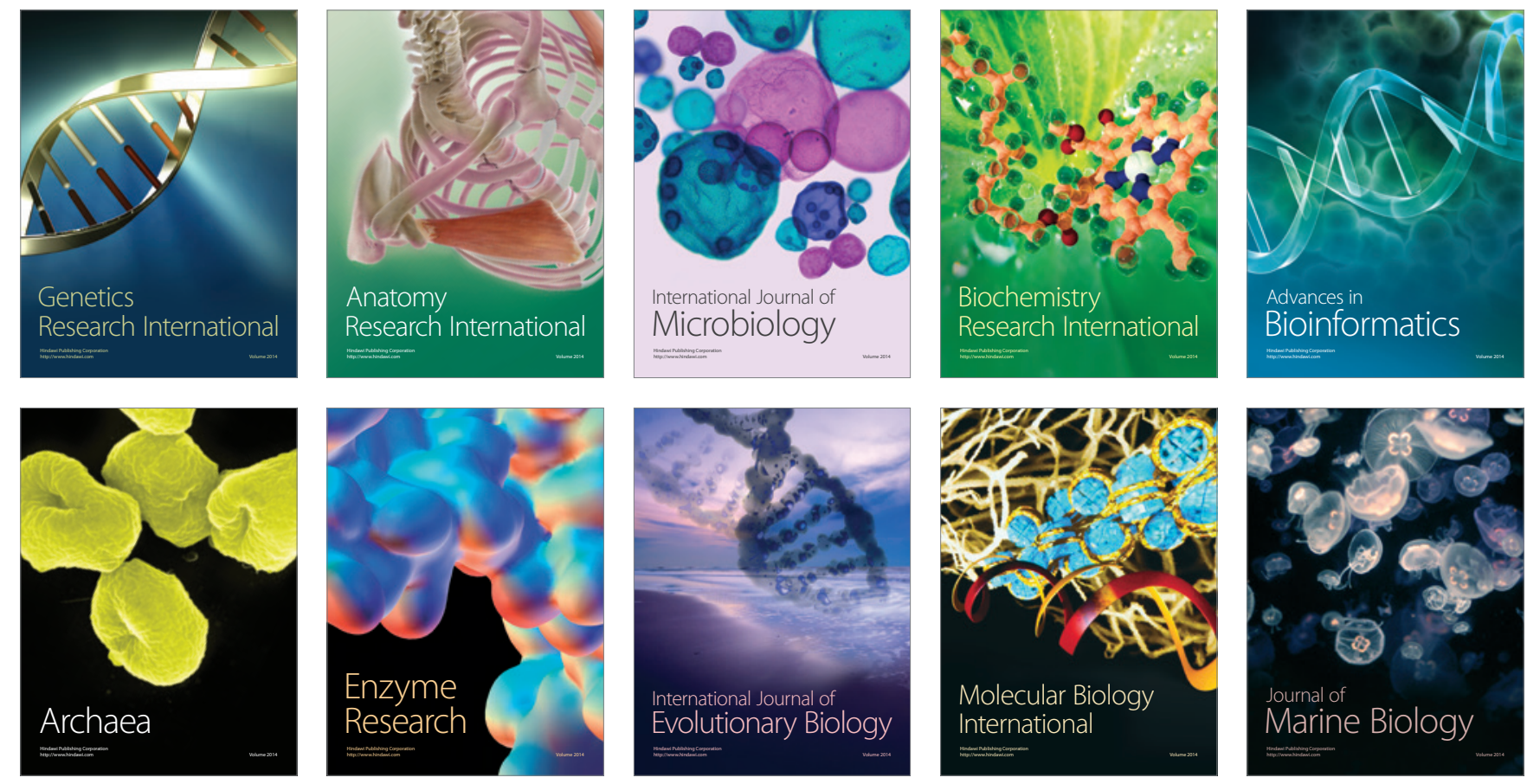